Research Article

\title{
Laser Treatment for Strengthening of Thin Sheet Steel
}

\author{
Oleksandr Kapustynskyi and Nikolaj Višniakov \\ Vilnius Gediminas Technical University, Sa1uletekio al. 11, LT-10223 Vilnius, Lithuania \\ Correspondence should be addressed to Nikolaj Višniakov; visnik@inbox.lt
}

Received 6 December 2019; Revised 10 February 2020; Accepted 4 March 2020; Published 26 March 2020

Academic Editor: Pavel Lejcek

Copyright (c) 2020 Oleksandr Kapustynskyi and Nikolaj Višniakov. This is an open access article distributed under the Creative Commons Attribution License, which permits unrestricted use, distribution, and reproduction in any medium, provided the original work is properly cited.

\begin{abstract}
This paper presents the results of computer simulations and experimental studies, aiming to increase the mechanical strength of sheet metal parts manufactured from high-quality structural carbon steel by means of local laser processing. The effects of laser processing on the strength of steel sheet plates and their ability to resist bend load after laser treatment were studied. The results of bending experiments and computer simulations of elastoplastic deformation establish that local laser processing with surface melting can be used to increase the mechanical strength of structural elements made from thin sheet steel C22E and to decrease its deflection under similar workload, as an alternative to the application of complex geometric shapes, additional strengthening elements, or heat treatment.
\end{abstract}

\section{Introduction}

Despite the availability of a wide range of durable and light materials in various areas of industry and engineering, steel is currently one of the most commonly used structural materials. Global steel production is increasing annually. The World Steel Association (worldsteel, WSA) predicted a rise in steel production by at least $1.4 \%$ in 2019. In 2018, according to the WSA, 1808.6 million tons of steel were manufactured, an increase of $4.6 \%$ compared to 2017 [1]. These data are based on the analysis of carbon steel manufacture in 64 countries, contributing about $99 \%$ of world steel production. High alloy stainless steels and special steels constitute a separate market and production segment. According to the International Stainless Steel Forum (ISSF), global steel production reached 50.7 million tons in 2018, rising by $5.5 \%$ compared to 48 million tons in 2017 [2]. These data suggest that carbon steels are still the most requested and most commonly used structural material.

Cheap, high-quality carbon steels are widely used to manufacture parts and metal products for noncritical structures in engineering and in other industries. Various carbon steels are widely used in welded structures [3]. The properties of carbon steels and semifinished steel products are highly dependent on their chemical composition, heat treatment method, and as-delivered state [4]. Steel production processes and the manufacture of various welded structures are quite simple and well established. However, carbon steels and low alloy steels widely used for these purposes have significant drawbacks. Structural carbon steel is fairly heavy, not very durable, and not resistant to corrosion [5]. Improvement of the mechanical properties (strength and hardness) of steel is a key factor to reduce the quantities of metal required by structures and to reduce the weight of metal parts.

In modern engineering practice, there are often problems whose solution involves taking into account the plastic properties of metals like steel. Taking into account the development of plastic deformations (ultimate load method or limit state design) during calculations and designs allows metal consumption to be reduced in comparison with the application of working stress methods. Heavily loaded structural elements, such as the shells of building structures, rockets, chemical reactors, thin-walled pipes, and other structures, are designed using calculation methods that take such plastic deformations into account. Since, in these cases, the systems are considered to be elastoplastic, the calculations are carried out outside the elasticity of the material. 
Using this approach, local plastic deformations are allowed in the calculations, i.e., the construction material no longer follows Hooke's law in the process of loading. Calculations taking into account plastic deformations often allow access to additional reserves of structural strength in steel structures and increase available workloads (in particular in the case of bending of rectangular profiles, up to $45 \%$ ) or ultimate bending moment (for beams, up to 1.5 times), in comparison with the results achieved by traditional working stress methods (only in elastic conditions) $[6,7]$.

The mechanical strength (includes compressive, tensile, and bending strength) of a steel structure is most important in many engineering applications. The application of heat treatment helps to increase the yield and ultimate strength of steels.

Another effective solution to increase strength (particularly bending strength) is changing the dimensions of parts, modifying the shape, or the application of special strengthening elements [8]. Techniques such as different heat-treatment or thermochemical-treatment processes and the addition of strengthening elements, complex-geometry profiles, and structural thickenings $[9,10]$ are mostly usable to improve the mechanical properties of steels products and their surface. However, these heat-treatment and thermomechanical-treatment technologies are expensive, complicated, and long-running processes. This technology is, therefore, not appropriate for large constructions and heavy sections from unalloyed and carbon steels containing less than $0.3 \%$ carbon, but thin plates and sheets from such steels can still be hardened and provide different combinations of strength and toughness after heat treatment. Application of strengthening elements, complex-geometry profiles, and structural thickenings increase the manufacturing costs and the weight of metal parts and require complex equipment and accurate designs.

Laser treatment is one popular technique of surface modification, which is designed to change the microstructure of metals through controlled heating and cooling. Laser surface treatment technologies (laser hardening, nitriding, and carburization) allow the enhancement of various properties, such as the surface strength, hardness, roughness, coefficient of friction, chemical resistance, and corrosion resistance of the surface of various metals [11]. Laser treatment technologies provide local heating, high-temperature gradients, and achievable cooling speed $\left(10^{5}-10^{6 \circ} \mathrm{C} /\right.$ s) due to thermal conductivity. In such conditions, the hardening of low carbon steels (such as high-quality carbon steel 10 or 20) is also possible [12]. The usual practice is the treatment of part of a large construction surface, which is possible with laser treatment technology.

Laser transformation hardening (LTH) is often used for surface hardening of cast iron, medium-carbon steel, and tool steel. LTH is a method in which a high-power laser beam quickly irradiates the surface of the workpiece to rapidly increase the surface temperature to a temperature higher than the austenite transformation temperature but lower than the melting point [13]; melting is usually undesirable in LTH [14]. The typical thickness of the hardened layer after transformation hardening by $\mathrm{CO}_{2}$ laser usually extends less than $0.3 \mathrm{~mm}$, applying a pulse laser, $0.15 \mathrm{~mm}$. By applying a more concentrated laser beam or powerful laser $(1 \mathrm{~kW})$, the depth of hardening can be increased up to $1.5 \mathrm{~mm}[15,16]$.

Most of the mixtures and composite materials properties, including their structural strength, follow the additivity rule and are linearly dependent on the percentage quantity or volume of individual components of the mixture. In this case, the approximate strength of dual-phase steels can be calculated according to the rules of mixtures [17]:

$$
\sigma_{\mathrm{c}}=\sigma_{\mathrm{m}} V_{\mathrm{m}}+\sigma_{\mathrm{r}} V_{\mathrm{r}}
$$

where $\sigma_{\mathrm{m}}$ is material property of matrix; $\sigma_{\mathrm{r}}$ is material property of reinforcement; $V_{\mathrm{m}}$ and $V_{\mathrm{r}}$ are volume fraction of matrix and reinforcement phase.

According to this rule, the efficiency of such laser processing and the final strength of the laser-treated zone depend on the total area of the processed zone and the depth of hardening. This means that the effectiveness of LTH is limited by the small thickness of the hardened layer, because a large area of the surface must be treated without melting. The "wide-spot" method uses a laser with a large spot, which moves evenly along a treated area. The scanning method uses a small laser spot in combination with a laser scanning head, which allows fast laser spot displacements. However, the LTH of large surface areas, large or thick-walled components, and the entire surface of metal parts is still complicated. Thus, LTH is mostly used for other purposes, for example, to improve the resistance of work surfaces to friction, wear, or corrosion through hardening. LTH without melting of the metal is not effective for the creation of specially oriented structural strengthening ribs, which strengthen metal constructions against outward deflection.

However, according to some research studies $[12,18,19]$, laser processing can be performed without melting of metal (when the temperature in the laser heated zone is close to melting temperature), as well as with melting (at higher temperatures), because the increase of hardness in the hardened zone and melted zones of hypoeutectoid carbon steel are similar. The difference comes from the presence of the melted zone and potential alterations in the hypereutectoid steel microstructure and the thickness of the hardened zone. Laser treatment with melting allows the greatest depth of treatment.

Due to phase transformations and local changes of material structure at the area of the laser beam exposure, it is possible to create structural strengthening ribs with better microstructure, which can significantly affect the overall strength of metal parts. Existing equipment and laser processing techniques offer ample opportunities to control the laser beam, which allows treatment of local areas, formation of structural strengthening ribs in the desired areas, and changing their orientation, disposition, depth, and other geometrical parameters of the treated layer [20]. This leads to better strength of the thin-walled metal parts.

The main objective of this study was to test the properties of the laser-melted layer and the efficiency of the application of laser processing with surface melting to increase the 
strength of thin sheet components manufactured from unalloyed and structural carbon steels containing less than $0.3 \%$ carbon, without the use of complex geometric structures or heat treatment.

The article presents the results of a study of the influence of laser treatment on the microstructure and mechanical properties of bent metal parts from hypoeutectoid highquality carbon steel. The effects of laser processing on the mechanical properties of steel sheet plates were studied, together with their ability to resist bending loads after laser treatment. The results of modeling of elastoplastic deformations of differently treated samples are compared and validated with results obtained by bending tests on real samples. The research results establish that local laser processing with surface melting can be used to increase the strength of structural elements made from thin sheet steel C22E and to decrease its deflection under similar workloads, as an alternative to the application of complex geometric shapes, additional strengthening elements, or heat treatment.

\section{Material}

One of the most common grades of high-quality structural carbon steel with carbon content less than $0.3 \%$ was used in an experiment. High-quality carbon steel is an alloy of iron and carbon with a low content of other chemical elements. Even small alterations in carbon and alloying elements content strongly affect the properties of the steel. These grades of steel are highly plastic and deformable [21].

Thin metal plates $(30 \times 150 \times 2 \mathrm{~mm})$ from hypoeutectoid high-quality carbon steel $20(1.1151, \mathrm{C} 22 \mathrm{E})$ were used as samples (Table 1). The mechanical properties of these steel sheets can vary, depending on the thermal or mechanical treatment applied (Table 2) [21, 22]. All the samples used were taken from one large sheet plate. The cutting orientation and preparation of the surface samples were identical. All the samples were heat-treated by tempering for stress relief. One side of the plate was mechanically processed to ensure uniform absorption of laser radiation on the steel surface. Sand blaster "Power Plus Tools" (China) and quartz sand "Sakret" (Germany) with a grain size of $0.1-0.5 \mathrm{~mm}$ were used for blast cleaning. The surface roughness $\mathrm{Ra}$ after the treatment did not exceed $5 \mu \mathrm{m}$.

The tests show that the chemical composition (Table 1) and mechanical properties (Tables 1 and 3) of the samples comply with the technical requirements listed in EN 100832:2006 [23].

\section{Methods}

3.1. Calculation of Laser Processing Modes and Laser Treatment Methodology. Laser surface treatment was carried out on the Nd:YAG 4-axis laser-welding machine BMM400 (China), of which the technical characteristics are presented in Table 4. During laser treatment, the metal plates were tightly fixed to a 3-coordinate metal table to avoid distortion of the samples. When using mild- or low-alloyed steel, Nd: YAG laser radiation is readily absorbed by the workpiece; therefore, there is no real need to use expensive inert shielding gas (pure Argon or gases mixtures with a helium content). A shielding gas mixture Ar- $\mathrm{CO}_{2}\left(20 \% \mathrm{CO}_{2}\right)$ was used for the Nd:YAG laser processing of the steel samples. The typical shielding gas flow rate of $20 \mathrm{l} / \mathrm{min}$ was used for prevention of metal oxidation.

The appropriate processing mode was calculated considering the physical properties of the metal (Table 5) and the technical limitations of the available laser equipment (Table 4), using the methodology presented in reference literature [24]. Parameters for laser processing in a pulse mode are mainly selected based on the critical energy density necessary for melting a given material. Melting or LTH of most metals proceeds at low energy density in the range of $10^{3}-10^{5} \mathrm{~W} / \mathrm{cm}^{2}$. The critical power density for local laser treatment in pulse mode can be calculated according to the equation given in [24]:

$$
P_{\mathrm{d}}=\frac{\rho\left(T_{\mathrm{e}}-T_{0}\right) \mathrm{ch}}{A t_{\mathrm{p}}},
$$

where $P_{\mathrm{d}}$ is critical power density $\left(\mathrm{W} / \mathrm{m}^{2}\right) ; A$ is absorptivity: $A=(1-R) ; R$ is reflection coefficient; $c$ is specific heat ( $\mathrm{J} /$ $(\mathrm{kg} \cdot \mathrm{K})) ; T_{0}$ is initial (room) temperature $(\mathrm{K}) ; T_{\mathrm{e}}$ is heating temperature, material melting, or evaporation temperature $(\mathrm{K}) ; \rho$ is density $\left(\mathrm{kg} / \mathrm{m}^{3}\right) ; t_{\mathrm{p}}$ is duration of laser pulse $(\mathrm{s}) ; h$ is thickness of the material or melted layer $(\mathrm{m})$.

The depth of penetration in this case should be minimal in order to avoid excessive embrittlement, cracking, and deformation of the treated material $[26,27]$. Mathematical calculations demonstrate that there are multiple options for local laser processing, depending on the required laser penetration depth, possible pulse duration, and diameter of the laser spot, as well as critical and peak power. The most appropriate laser processing parameters for the available equipment were selected according to the mathematical calculations. The selected parameters (laser spot diameter, laser speed, pulse time, pulse frequency, and energy per pulse) remained constant throughout all experiments. The alterable parameters are the number of laser tracks and the distance between them. 3 variants of distance between lasertreated tracks were applied: a-tracks with $30 \%$ overlap of their width (56 tracks), b-distance between tracks equal approximately to $50 \%$ of their widths (27 tracks), and $c$-distance between tracks equal to their widths (21 tracks). The dimension of the laser-treated surface area in all cases was $40 \times 29 \mathrm{~mm}$.

3.2. Testing of Laser-Processed Surface Layer Properties and Analysis Microstructure. The structure, chemical composition, and mechanical properties of the steel were determined in order to establish the input data for the FEA simulation. The chemical composition of the steel was determined by spectral analysis using the PMI Master PRO Oxford Instruments (UK) optical emission spectrometer. The mechanical properties of the steel were established by standard tensile and hardness tests according to ISO 6892-1:2016 [28]. For the tensile testing, a universal tensile-testing machine TIRAtest 2300 (Germany) with Katman-Express software 
TABLe 1: Chemical composition \% of steel C22E (1.1151) [23].

\begin{tabular}{lcccccc}
\hline Chemical elements (wt.\%) & $\mathrm{C}$ & $\mathrm{Si}$ & $\mathrm{Mn}$ & $\mathrm{P}$ & $\mathrm{S}$ & $\mathrm{Cr}+\mathrm{Mo}+\mathrm{Ni}$ \\
\hline Typical composition of steel according to EN 10083-2:2006 & $0.17-0.24$ & Max 0.4 & $0.4-0.7$ & Max 0.03 & Max 0.035 & Max 0.63 \\
Sample & 0.17 & 0.13 & 0.44 & 0.02 & 0.02 & 0.12 \\
\hline
\end{tabular}

TABLE 2: Mechanical properties of steel C22E (1.1151) according to standard EN 10083-2:2006 [23].

\begin{tabular}{lcccc}
\hline Heat treatment & $\begin{array}{c}\text { Yield strength }(\mathrm{MPa}) \\
\text { Min }\end{array}$ & $\begin{array}{c}\text { Ultimate tensile strength (MPa) } \\
\text { Min }\end{array}$ & $\begin{array}{c}\text { Elongation (\%) } \\
\text { Min }\end{array}$ & $\begin{array}{c}\text { Hardness }(\mathrm{HB}) \\
\text { Max }\end{array}$ \\
\hline Rolled & & 490 & 7 & 207 \\
Annealing or tempering $600\left({ }^{\circ} \mathrm{C}\right)$ & 230 & 390 & 21 & 163 \\
Normalizing 900 $\left({ }^{\circ} \mathrm{C}\right)$ & 240 & 430 & 24 & $101-143$ \\
Quenching 880 $\left({ }^{\circ} \mathrm{C}\right)$ & 340 & 590 & 18 & 370 \\
Quenching $880^{\circ} \mathrm{C}+$ tempering $600\left({ }^{\circ} \mathrm{C}\right)$ & 340 & $500-650$ & 20 & $143-179$ \\
\hline
\end{tabular}

TABLE 3: Results of mechanical tensile tests of steel samples.

\begin{tabular}{lcccc}
\hline Elastic modulus $E(\mathrm{GPa})$ & Yield strength $R_{0.2}(\mathrm{MPa})$ & Tensile strength $R_{\mathrm{m}}(\mathrm{MPa})$ & Relative extension A (\%) & Hardness $(\mathrm{HV})$ \\
\hline 200 & 275 & 450 & 32 & 135 \\
\hline
\end{tabular}

TABle 4: Technical data of [24].

\begin{tabular}{lc}
\hline Technical parameters & Range \\
\hline Laser working substance & Nd:YAG \\
Maximum single-pulse energy $(\mathrm{J})$ & 150 \\
Maximum peak power $(\mathrm{kW})$ & 14 \\
Laser wavelength $(\mathrm{nm})$ & 1064 \\
Spot size diameter $(\mathrm{mm})$ & $0.1-3.0$ \\
Average laser power $(\mathrm{W})$ & 400 \\
Pulse duration $(\mathrm{ms})$ & $0.5-10$ \\
Pulse frequency $(\mathrm{Hz})$ & $0-20$ \\
\hline
\end{tabular}

TABLE 5: Physical properties of carbon steel [25].

\begin{tabular}{lcccc}
\hline $\begin{array}{l}\text { Melting temperature, } \\
T_{\mathrm{m}}(\mathrm{K})\end{array}$ & $\begin{array}{c}T_{0} \text {-initial (room) } \\
\text { temperature }(\mathrm{K})\end{array}$ & Absorptivity, $A$ & $\begin{array}{c}\text { Reflection } \\
\text { coefficient, } R\end{array}$ & $\begin{array}{c}\text { Density, } \rho \\
\left(\mathrm{kg} / \mathrm{m}^{3}\right)\end{array}$ \\
\hline 1733 & 295 & 0.09 & 0.91 & $\begin{array}{c}\text { Specific heat, } c \\
(\mathrm{~J} / \mathrm{kg} \cdot \mathrm{K})\end{array}$ \\
\hline
\end{tabular}

was used (dynamometer up to $50 \mathrm{kN}$ ). The precision of testing equipment, load, and deformation measurement sensors was $\pm 0.03 \%$. Steel hardness was determined using Zwick/Roell ZHU universal hardness tester, using the Vickers method with a square-based tetrahedral pyramid. Steel hardness was determined on the surface with a load of $10 \mathrm{~N}$. The hardness of the laser-processed surfaces was determined using Zwick/Roell $\mathrm{ZH} \mu$ hardness tester (Swiss), with a diamond square-based tetrahedral pyramid tip with a load of $2.942 \mathrm{~N}$. Hardness was measured on the surface of the processed layers and on its cross section according to EN ISO 4516 [29].

Macroscopic and microscopic examination of lasertreated samples was done according to ISO 17639:2003. Metallographic analysis of the steel and of the laser-processed zones was carried out using a Nikon Eclipse MA200 optical microscope (Japan) with Lumenera Infinity 2-2 video camera and a JEOL JSM-7600 (Japan) scanning microscope, equipped with an energy-dispersive spectrometer (EDS) Oxford INCA Energy X-Max20 (UK) for chemical microanalysis at different magnifications (up to $\times 1500$ ). Etchants for macroscopic and microscopic examination were selected according to ISO/TR 16060:2003. A Nital solution (3 wt.\% concentrated nitric acid in ethyl alcohol) was used for etching the steel samples.

3.3. Simulation of Elastoplastic Bending of Metal Sheet. Thin-walled metal parts manufactured from steel, which are most often stressed by bending load, are modeled using finite element analysis (FEA) [11]. The simulation of the elastoplastic deformation of the plates under bending load was done using a device model analogous to that used in metal bend tests according to ISO 7438:2016 [30]. The 3D mode was created and subsequently converted to STEP format using the Autodesk Inventor software package. An Ansys Workbench software package was used in the second step for computer simulation of the deformations in a laser-processed thin plate acted on by a bending load. The size of the $3 \mathrm{D}$ model and the shape and depth of the processed layer 
were the same as in the real samples (Figures 1-3). Boundary conditions, maximum applied load $(1280 \mathrm{~N})$, and maximum deflection $(2 \mathrm{~mm})$ in the bending simulation were identical to those used during the experimental bend tests. The structural supports were modeled as roller movable supports. The punch rounding radius, width $(10 \mathrm{~mm})$, and distance between supports $(40 \mathrm{~mm})$ were the same as in the real bending test.

Several variants of metal plate processing with different degrees of overlapping (distance between the layers) processed by laser beam were simulated to assess the influence of the geometry of the treated layer on the required bending load and mechanical strength of the metal sample. 4 variants of the model with different geometry of the treated layers were applied in the simulations: a-unprocessed plate (case A); b-laser track with a $30 \%$ overlap of its width (case B), c-distance between laser tracks equal approximately to $50 \%$ of their widths (case C), and d-distance between tracks equal to their widths (case D) (Figures 2 and 3). The treated layers were oriented in the direction of the greatest stresses, by analogy with the strengthening of composite materials with longitudinal strengthening elements. The total treated area $(40 \times 29 \mathrm{~mm})$, localization of processed layers, and depth of fusion $(0.35 \mathrm{~mm})$ remained unchanged (Table 6).

A mixture of 3D Solid brick and tetrahedral elements was used to mesh the model of the metal plate [31]. The untreated part of the model metal plate consists mostly of large-scale elements with maximum mesh size of $0.7 \mathrm{~mm}$. The mesh density of the treated area was increased but the maximum mesh size was less than $0.12 \mathrm{~mm}$. The numerical investigation of the physically nonlinear problem was solved for the bending case. For FEA, the relatively simple plasticity model-Multilinear Isotropic Hardening model-was used [32]. The stress-strain curves of the basic metal and the treated layer are provided from experimental data, but the dependences of the nonlinear part of the curves are simplified to linear, which is traditionally used for the Bilinear Isotropic Hardening model; then, only the yield strength and the tangent modulus of the material are used as input parameters (Figure 4).

The total deformation in the model is represented as the sum of the elastic and plastic deformation components $[11,33]$ :

$$
\varepsilon=\varepsilon^{e}+\varepsilon^{p},
$$

where $\varepsilon^{e}$ is elastic deformation and $\left\{\varepsilon^{p}\right\}$ is plastic deformation.

Two different material properties were used in the FEA model: the base steel and laser-treated steel (Table 7). Base steel properties are applied in modeling Case A and in models of Cases B, C, and D for the area outside the semicircles (Figure 3). Treated steel properties are applied in modeling Cases B, C, and D in the areas inside the semicircles (Figure 3). The mechanical properties of the steel used in the simulation were established by mechanical (tensile and bending) testing of specimens and applying the published information [34-36]. The mechanical properties of the laser-processed zones were determined through measurement of their hardness, analysis of the microstructure, and the application of parameter values picked from examples in the published literature [34], calculated using empirical equations (1), (4), and (5) (Table 7).

Expressions related to the hardness, tensile strength, and yield strength of steels and laser-processed layers were used for the calculation of mechanical strength [37-39]:

$$
\begin{aligned}
\sigma_{\mathrm{B}} & =\frac{\mathrm{HV}}{2.9}\left(\frac{n}{0.217}\right)^{n}, \\
\sigma_{0.2} & =\frac{\mathrm{HV}}{3} 0.1^{n},
\end{aligned}
$$

where $\sigma_{\mathrm{B}}$ and $\sigma_{0.2}$ are tensile strength and yield strength, respectively; $n$ is strain-hardening exponent (for carbon steel $n$ is in the range from 0.15 to 0.26 ) [34-36].

3.4. Measuring of Deflection of Metal Sheet. For the bend test, a universal tensile-testing machine TIRAtest 2300 (Germany) was used, with a bending test tool and KatmanExpress software (dynamometer up to $2 \mathrm{kN}$ ). The precision of testing equipment, load, and deformation measurement sensors was $\pm 0.03 \%$. The distance between supports was $40 \mathrm{~mm}$, punch width was $10 \mathrm{~mm}$, maximum load used was $1280 \mathrm{~N}$, and the maximum deflection was $2 \mathrm{~mm}$. The distance between supports was set longer than that required in ISO 7438:2016 [30] for the bend test and equal to the length of the laser treatment area. These experimental conditions would be appropriate for the purpose of simulating the case of bending a thin-walled plate with strengthening ribs or a surface fully treated by laser.

\section{Results}

4.1. Results of the Calculations of Laser Processing Modes. One of the criteria for the selection of appropriate processing modes was the required depth of laser penetration. An appropriate depth of laser penetration is about $0.35 \mathrm{~mm}$ ( $20 \%$ of the total thickness of the metal sheet). This value was based on previous research [20] with similar thin sheet steel, when various technological parameters of laser were applied, and shape, microstructure, and surface defects of the processed layers were analyzed. The critical power of $3.98 \cdot 10^{5} \mathrm{~W} / \mathrm{cm}^{2}$ and other selected laser treatment parameters (Table 8 ) ensure that the depth of the metal melting zone will reach the required value.

\subsection{Results of the Study of Laser-Processed Surface Layer} Properties and Microstructure. The metallographic analysis of sections indicated that the expected thickness (depth) of the treated layer $(0.35 \mathrm{~mm})$ was achieved using the calculated parameters of the laser beam in the experiments. The surface of the treated area was free from superficial defects and other indications of improper laser treatment (Figure 5). The shape of the laser track was close to hemispherical (Figure 6). The same layer shape was used in FEA simulations (Figures 1-3). 

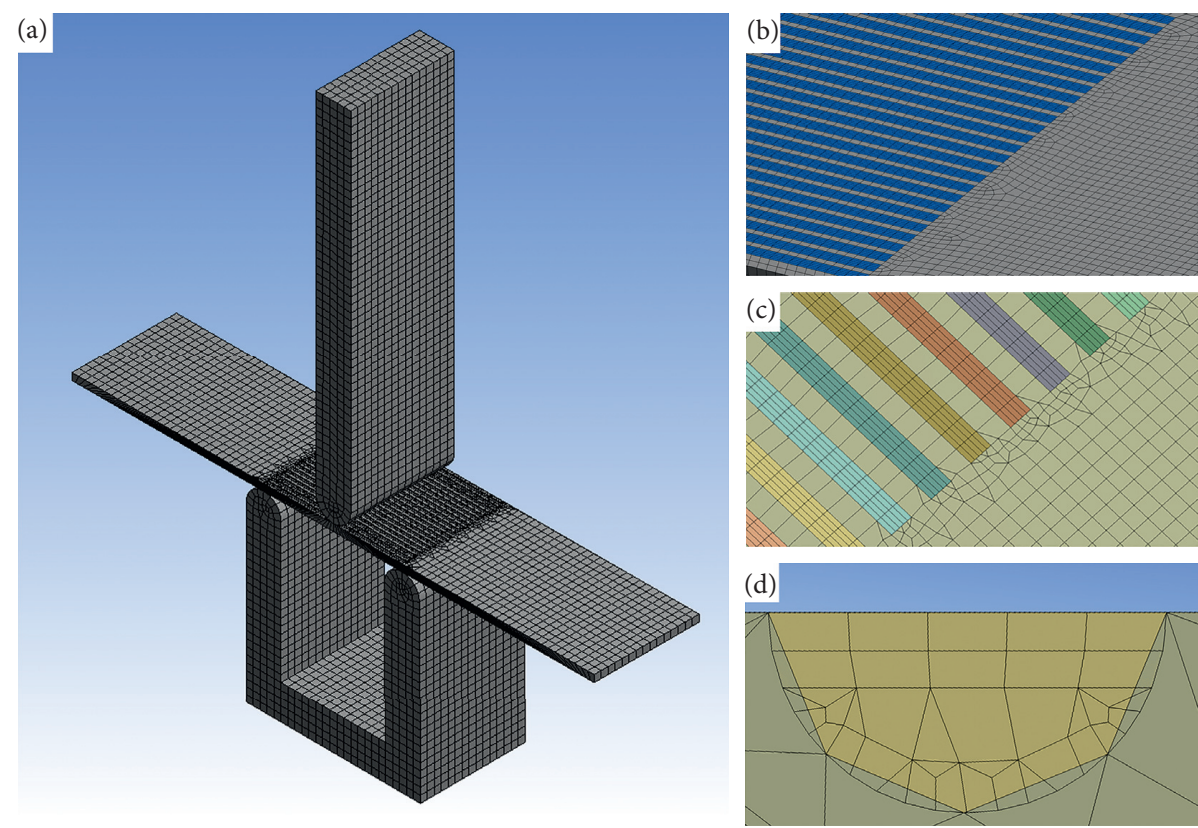

Figure 1: Finite element mesh of a model in Ansys workbench: (a) general view of 3D mesh, (b) enlarged view of mesh of laser tracks, (c) enlarged view of surface mesh of treated area, and (d) cross-sectional view of mesh of individual laser track.
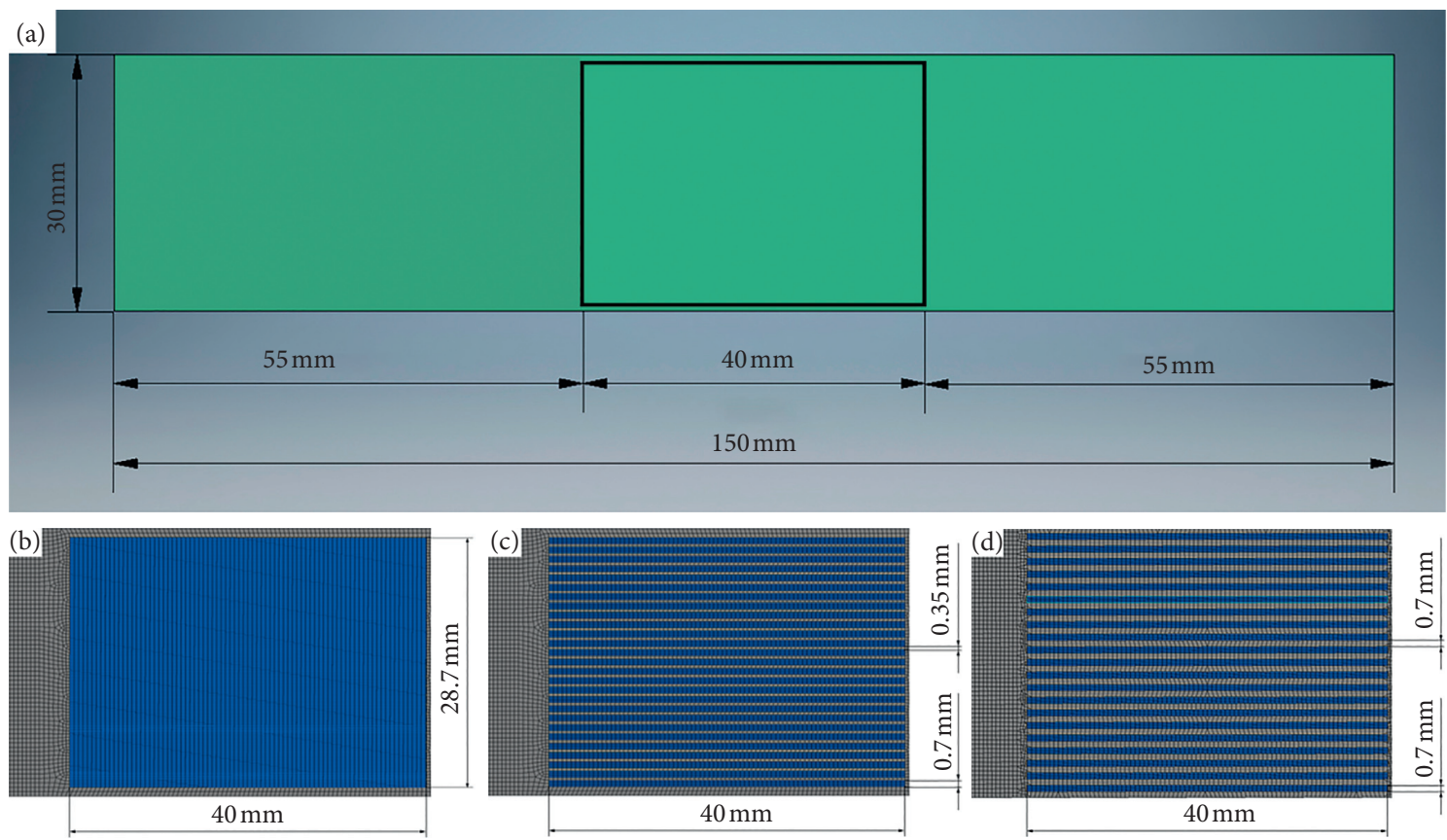

Figure 2: Views of the surface of samples in Ansys software: (a) general view of metal plate with dimensions of treated area. (b) Case B. (c) Case C. (d) Case D.
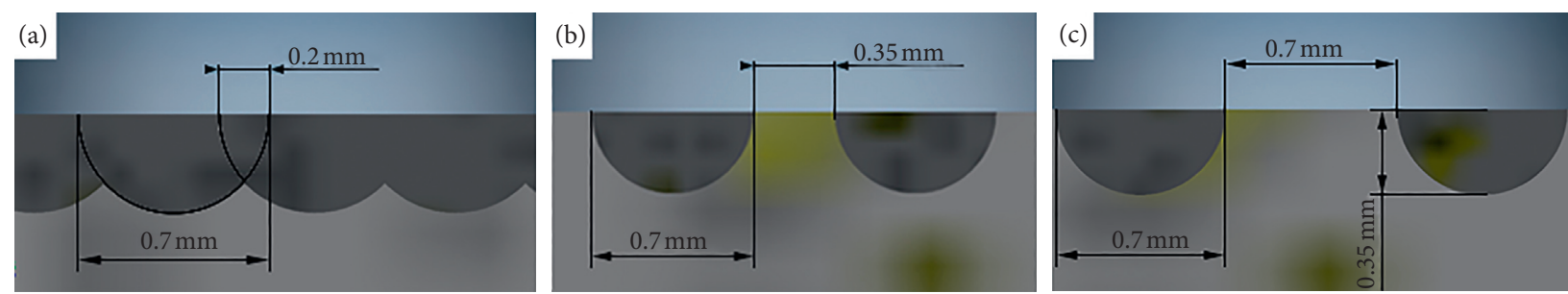

Figure 3: Cross-sectional view of laser-treated zones in Autodesk Inventor software. (a) Case B. (b) Case C. (c) Case D. 
Table 6: The geometry of treated area.

\begin{tabular}{|c|c|c|c|}
\hline Samples & Case B & Case $\mathrm{C}$ & Case D \\
\hline Radius of individual track $(\mathrm{mm})$ & 0.35 & 0.35 & 0.35 \\
\hline Treated surface, length $\times$ width $(\mathrm{mm} \times \mathrm{mm})$ & $40 \times 29$ & $40 \times 29$ & $40 \times 29$ \\
\hline Number of laser tracks in treated area (pc) & 56 & 27 & 21 \\
\hline Volume of treated area $\left(\mathrm{mm}^{3}\right)$ & 406 & 270.7 & 161.55 \\
\hline Ratio of volume of treated area related to the total bent volume (\%) & 16.92 & 11.28 & 6.73 \\
\hline
\end{tabular}

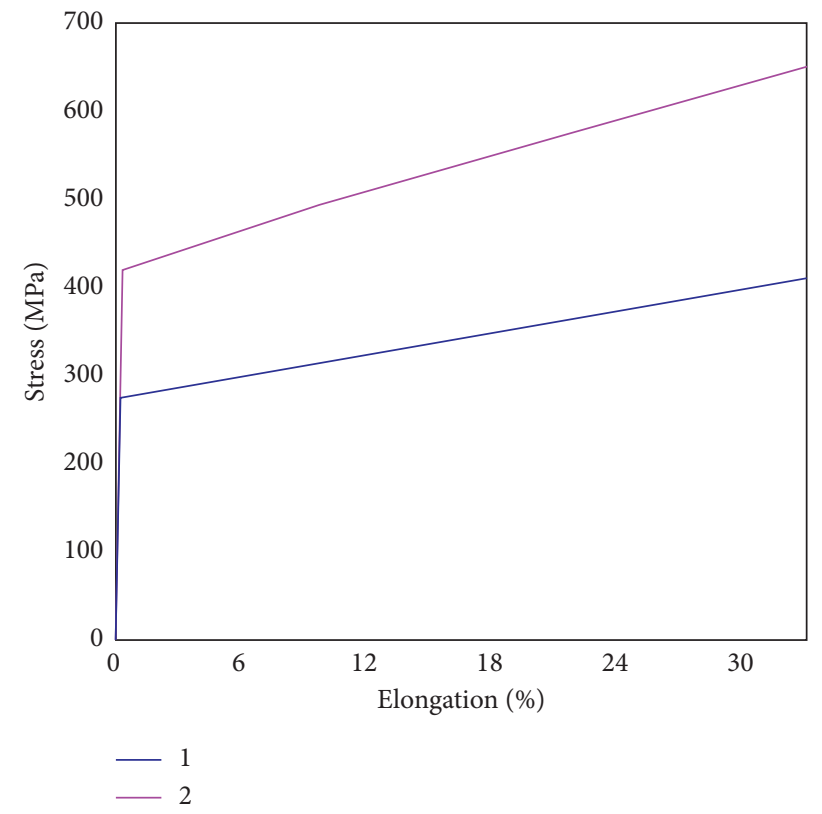

Figure 4: Deformation curves: (1) untreated metal; (2) area treated by laser.

TABLe 7: Parameters of steel and laser-treated surfaces used to calculate elastoplastic deformation of samples.

\begin{tabular}{lccccc}
\hline Material & $\begin{array}{c}\text { Modulus of elasticity, } E \\
(\mathrm{GPa})\end{array}$ & $\begin{array}{c}\text { Shear modulus, } G \\
(\mathrm{GPa})\end{array}$ & $\begin{array}{c}\text { Yield strength, } \sigma_{0.2} \\
(\mathrm{MPa})\end{array}$ & $\begin{array}{c}\text { Ultimate strength, } \sigma_{\mathrm{B}} \\
(\mathrm{MPa})\end{array}$ & $\begin{array}{c}\text { Poisson's ratio } \\
(\nu)\end{array}$ \\
\hline $\begin{array}{l}\text { Base metal (steel } \\
\text { C22E) }\end{array}$ & 200 & 78.1 & 275 & 450 & 0.28 \\
Laser-treated layer & 210 & 82 & 412 & 665 & 0.28 \\
\hline
\end{tabular}

TABle 8: Parameters of local laser processing.

\begin{tabular}{|c|c|c|c|c|c|c|c|c|}
\hline $\begin{array}{l}\text { Depth } h \\
(\mathrm{~mm})\end{array}$ & $\begin{array}{l}\text { Speed, } v \\
(\mathrm{~mm} / \mathrm{min})\end{array}$ & $\begin{array}{l}\text { Frequency, } f \\
(\mathrm{~Hz})\end{array}$ & $\begin{array}{l}\text { Single pulse } \\
\text { energy, } E_{\mathrm{p}}(\mathrm{J})\end{array}$ & $\begin{array}{l}\text { Spot size, } \\
d(\mathrm{~mm})\end{array}$ & $\begin{array}{c}\text { Peak power, } \\
P_{\mathrm{p}}(\mathrm{kW})\end{array}$ & $\begin{array}{c}\text { Overlap } \\
\text { coefficient, } P_{\text {er }} \\
(\%)\end{array}$ & $\begin{array}{l}\text { Calculated critical } \\
\text { power, } P_{\mathrm{d} 1}\left(\mathrm{~W} / \mathrm{cm}^{2}\right)\end{array}$ & $\begin{array}{c}\text { Real critical } \\
\text { power, } P_{\mathrm{d} 2} \text {, (W/ } \\
\left.\mathrm{cm}^{2}\right)\end{array}$ \\
\hline 0.346 & 240 & 10 & 14.4 & 3 & 2.8 & 98.6 & $4.11 \cdot 10^{5}$ & $3.98 \cdot 10^{5}$ \\
\hline
\end{tabular}

The analysis of metallographic sections shows that local laser processing of sheet steel C22E causes local changes of its microstructure. The structure of the crystal lattice of steel in the heated and remelted zones is modified, turning from ferritepearlite structure (characteristic of carbon steel C22E after tempering or normalizing) into a sorbite structure (Figure 7), i.e., ferrite-cementite mixture, which has more fine texture than pearlite. The distance between lamellae in the obtained dispersed sorbite structure was about 0.4 micrometers and its grain size was G11 $[4,40]$. In general, sorbite is formed during accelerated cooling of decomposing austenite in the temperature range of $600-700^{\circ} \mathrm{C}$ or during tempering of martensite. Sorbite structure has higher dispersity and hardness, which increases the strength, resistance to cyclic loading, and wear resistance of metal parts without loss in plasticity [41]. The series of measurements of microhardness in this case shows that the hardness of the processed layer increases by $50 \%$ (up to $205 \mathrm{HV}$ ) compared to the untreated zone, where hardness did not exceed $135 \mathrm{HV}$ (Figure 8). The hardness in the overlapping area of the tracks is very similar to the hardness in the middle of the laser-treated area, which was in the range of 195-205 HV. 

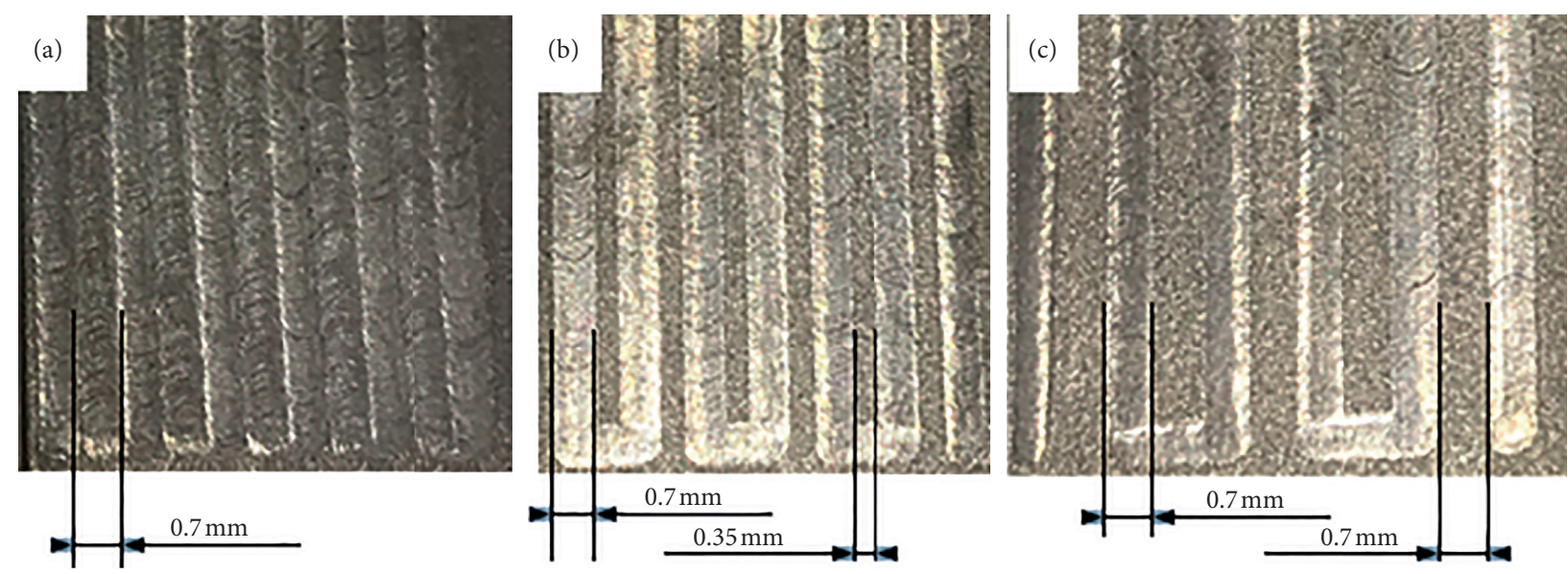

Figure 5: General view of laser-treated area. (a) Case B. (b) Case C. (c) Case D.
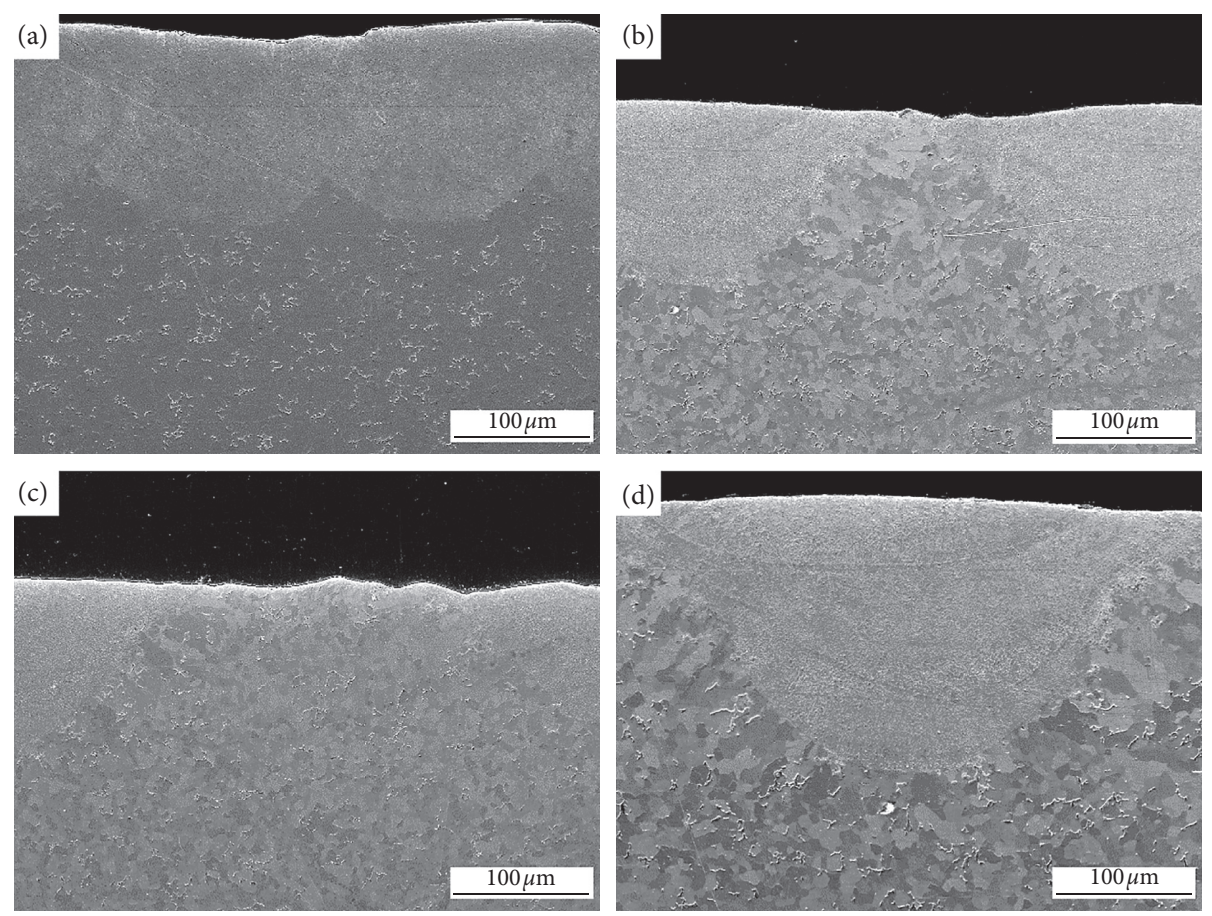

FIgURE 6: Sectional view of laser-treated area. (a) Case B.

(b) Case C. (c) Case D. (d) Shape of a separate laser track.

No hard and brittle quenching structures or other undesirable inclusions and internal defects were formed in the laser-processed (remelted) layer or along the edge of melted zones (Figures 9 and 10).

Grain size in the processed zone decreased from G8 (average grain diameter about $20 \mu \mathrm{m}$ ) to G11 (average grain diameter about $7 \mu \mathrm{m}$ ). The presence of the sorbite and the absence of hard and brittle quenching structures were also confirmed by measurements of microhardness on metallographic sections (Figure 8). A study of the distribution of chemical elements in the processed (remelted) layer showed that there was no significant chemical heterogeneity in this area. SEM-EDS element mapping, line scan, and point analysis of the distribution and concentration of chemical elements show that the distributions of $\mathrm{C}, \mathrm{Mn}$, and $\mathrm{Si}$ are fairly uniform across the sample (Table 9).
4.3. Results of the Deformation Simulation of Elastoplastic Bending of Metal Sheet. The simulation results of 4 developed models (Figures 1-3) were subjected to a comparative analysis of stresses and strains under different load and deflection (Figure 11). The required bending loads for samples deflection till $0.5,1,1.5$, and $2 \mathrm{~mm}$ were determined by FEA.

The model was validated by comparing the results of bending tests with the results of the modeling of samples. Experimental results and deflection simulation results of untreated samples were compared with the results of samples treated, applying different distances between laser tracks.

The results of bending experiments and calculation according to the rules of mixtures (equation (1) showed that the average yield strength and ultimate strength of laser- 

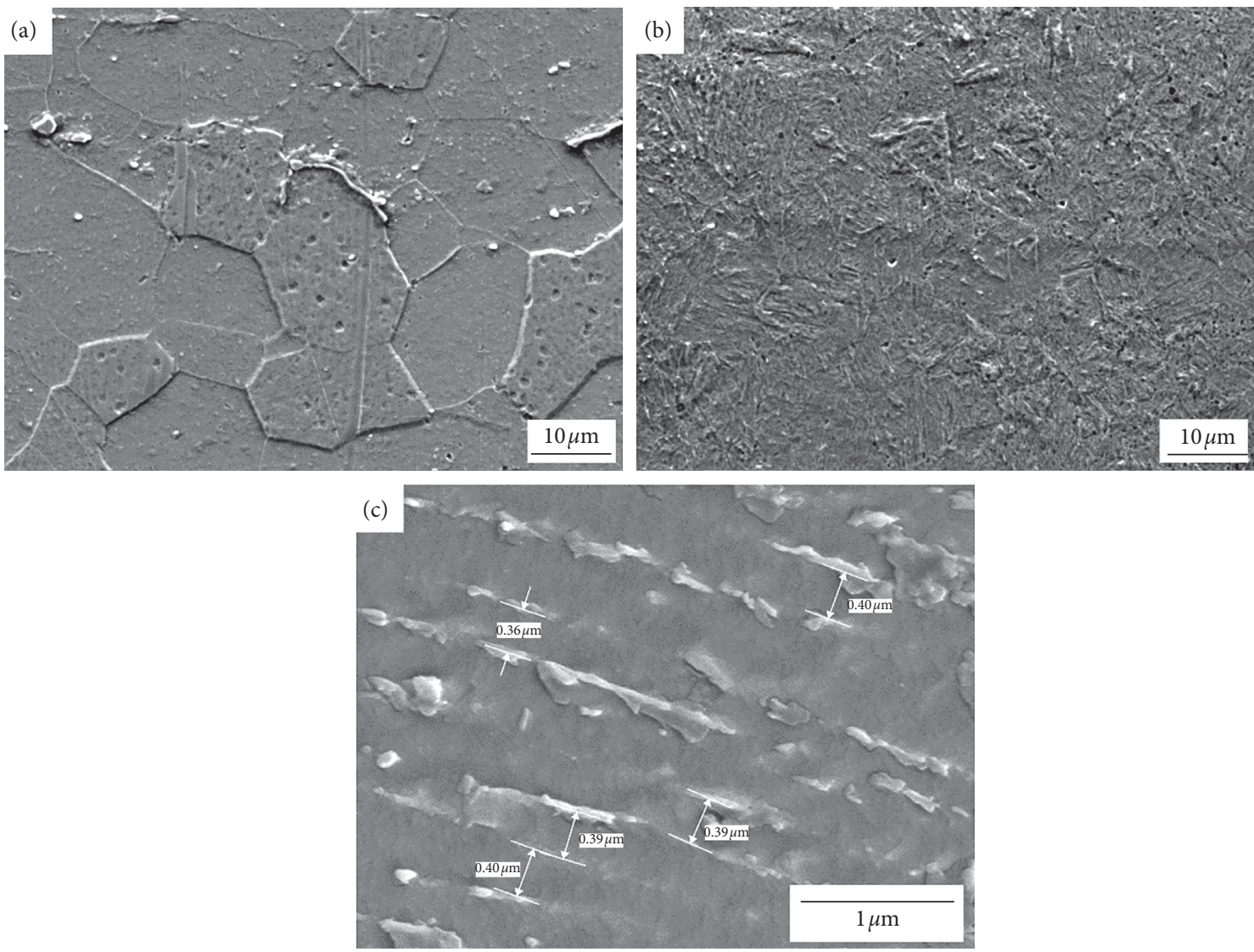

FIGURE 7: Microstructure of steel: (a) untreated area of steel with ferrite-pearlite structure (65\% ferrite and $35 \%$ pearlite according to GOST 8233-56 [40], grain size G8 according to ISO 643:2012 [42], magnification $\times 1500$ ), (b) laser-treated layer (dispersed sorbite structure, grain size G11 according to ISO 643:2012 [42], magnification $\times 1500$ ), and (c) laser-treated layer (dispersed sorbite structure, according to GOST 8233-56 [40], magnification $\times 20000)$.

processed metal sheets increase from $3.4 \%$ to $8.4 \%$, depending on the quantity of laser tracks and the volume of the treated area in comparison to untreated samples (Table 10)). It is established that metal sheets with $30 \%$ overlay of laser tracks have the highest mechanical strength compared to the other treatment modes (Tables 11 and 12).

However, simulations suggest that, in practice, it is also possible to use noncontinuous processing (with a certain distance between tracks) because the difference in the efficiency of such processes is small. After local laser processing, the load required for $0.5 \mathrm{~mm}$ deflection in the elastic stage increased by $25-32 \%$ in comparison with untreated plates. When an external load of $700 \mathrm{~N}$ was applied (conditions where internal stresses are close to this steel's yield strength), the plate deflection was reduced by $8-18 \%$ depending on the processing mode (applied distance between laser tracks).

4.4. Experimental Results of the Deflection Analysis of Elastoplastic Bending of Metal Sheet. The mechanical bend tests showed that local laser processing increases the mechanical strength of samples in comparison with untreated samples (Figure 12 and Table 13). The bending force-deflection curve of each case was drawn using the average data of 3 tests. From Figure 12, it is visible that a larger load was required to reach

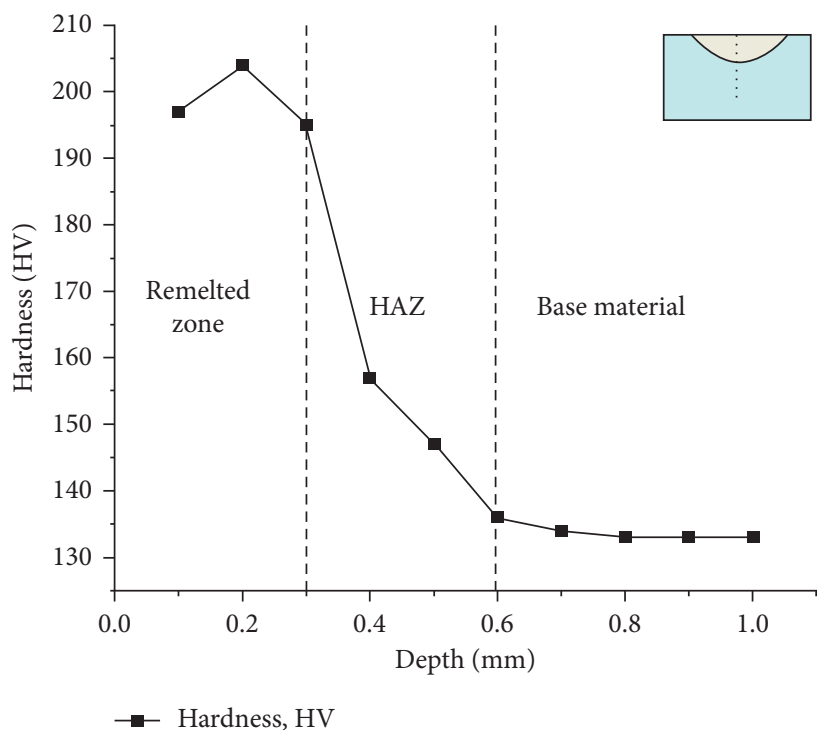

Figure 8: Microhardness distribution in the laser-treated layer.

the same level of deflection for the laser-processed samples compared to the untreated ones. The maximum bending load to reach the limit of deflection in the elastic stage varied in the 

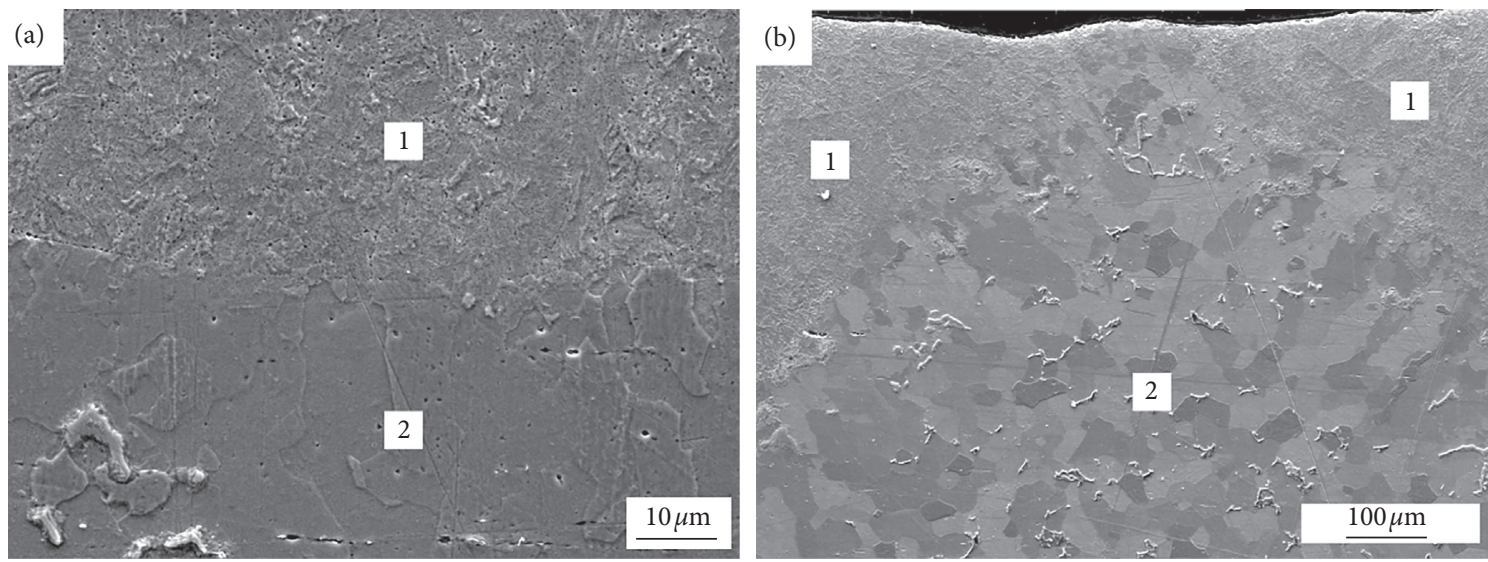

FIGURE 9: Microstructure of the transition zone: (a) magnification $\times 1000$; (b) magnification $\times 250$; (1) surface layer after laser processing; (2) untreated zone.
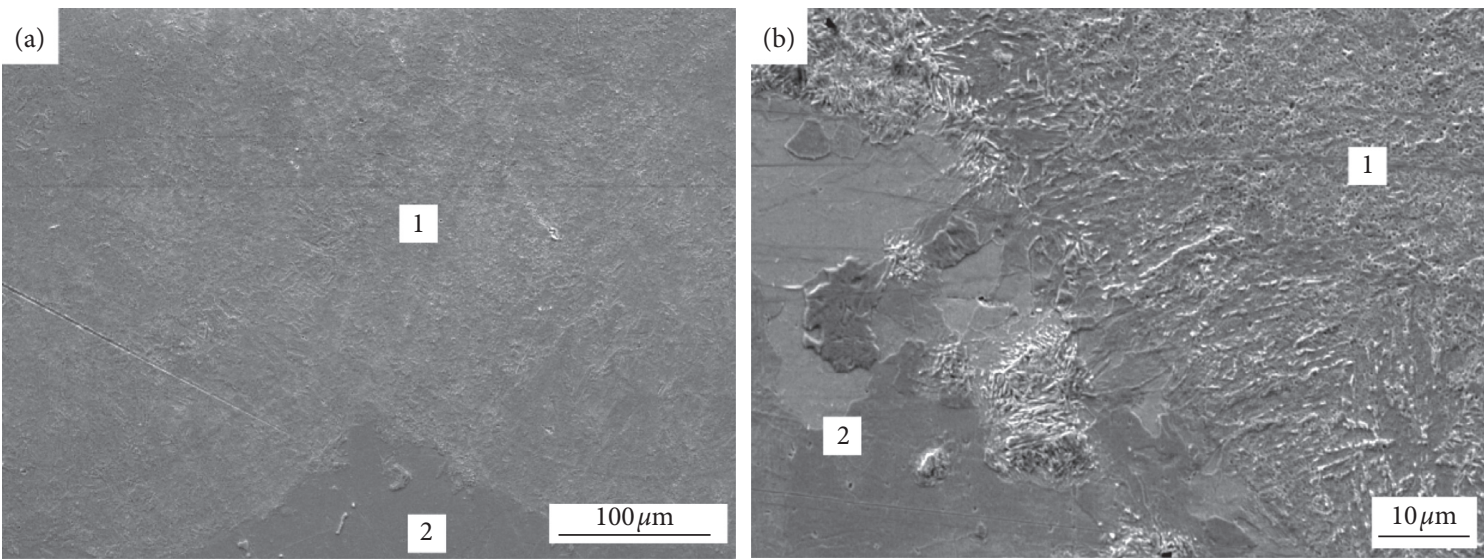

Figure 10: Microstructure in the zone of overlapping of individual tracks: (a) magnification $\times 250$; (b) magnification $\times 1000$; (1) surface layer after laser processing; (2) untreated zone.

Table 9: Chemical compositions (by energy-dispersive X-ray spectroscopy analysis) of regions 1 and 2, Figure 9(a).

\begin{tabular}{lccccc}
\hline \multirow{2}{*}{ Region } & \multicolumn{3}{c}{ Chemical elements (wt.\%) } \\
& $\mathrm{C}$ & $\mathrm{Fe}$ & $\mathrm{Si}$ & $\mathrm{Mn}$ & Other \\
\hline Area treated by laser & 3.52 & 95.20 & 0.33 & 0.39 & 0.56 \\
Basic metal & 2.31 & 96.50 & 0.33 & 0.40 & 0.46 \\
\hline
\end{tabular}

TABLE 10: Mechanical properties of bent plates.

\begin{tabular}{|c|c|c|c|c|}
\hline Characteristics & Case A & Case B & Case $\mathrm{C}$ & Case D \\
\hline Poisson ratio $(\nu)$ & 0.28 & 0.28 & 0.28 & 0.28 \\
\hline Modulus of elasticity $E(\mathrm{GPa})$ & 200 & 202.89 & 201.13 & 200.67 \\
\hline Yield strength $\sigma_{0.2}(\mathrm{MPa})$ & 275 & 298.18 & 290.45 & 284.22 \\
\hline Ultimate strength $\sigma_{\mathrm{B}}(\mathrm{MPa})$ & 450 & 486.38 & 474.25 & 464.47 \\
\hline
\end{tabular}

range from $699 \mathrm{~N}$ to $821 \mathrm{~N}$, depending on the mode of treating, which is equal to a $17 \%$ increase in load. The elastic deflection of the samples varied from $0.75 \mathrm{~mm}$ to $0.95 \mathrm{~mm}$, depending on the mode of laser treatment.

The load required to reach a $2 \mathrm{~mm}$ deflection in the plastic stage was $1000 \mathrm{~N}$ for the untreated samples and $1200 \mathrm{~N}$ for the laser-treated samples, which is equal to a $20 \%$ increase in load. Experimental data confirmed that the strengthening and the total increase in bending load (when treated by the laser area and achieved deep of penetration of all samples are constant) are influenced by the distance between laser tracks, which in turn affects the volume of the hardened phase and its ratio to the volume of untreated material in the bent area. The maximum difference between the experimental and computational modeling results is less than $6 \%$ (Table 14). 


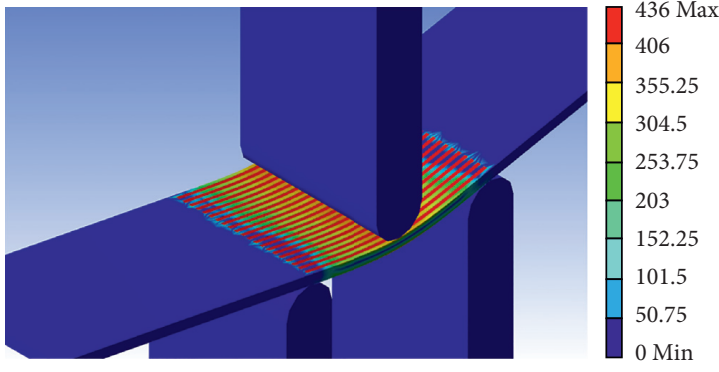

(a)

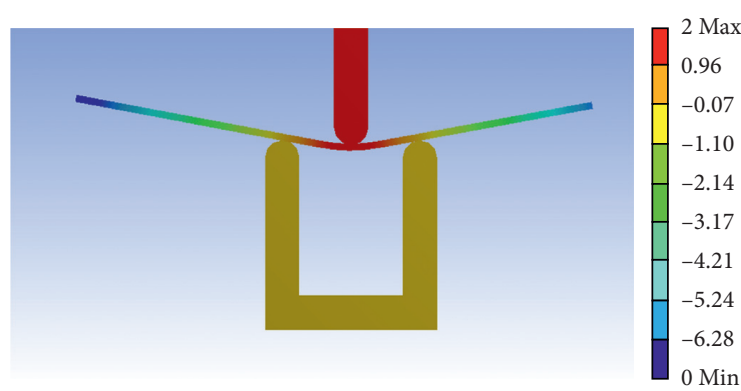

(b)

Figure 11: Computer simulation of bending test in Ansys workbench: (a) stress distribution in a bent element; (b) strains degree of the bent element under load.

TABLE 11: Results of computer simulation of the elastoplastic deformation in the plates (with $2 \mathrm{~mm}$ deflection).

\begin{tabular}{|c|c|c|c|c|}
\hline Objects & Case A & Case B & Case $\mathrm{C}$ & Case D \\
\hline Bending strain $w(\mathrm{~mm})$ & 2 & 1.98 & 1.99 & 2 \\
\hline Maximum von Mises equivalent stress $(\mathrm{MPa})$ & 416 & 462 & 444 & 436 \\
\hline Bending force $P(\mathrm{~N})$ & 1033 & 1280 & 1217 & 1167 \\
\hline
\end{tabular}

TABLE 12: Results of computer simulation of the elastic deformation in the plates (with a load of $700 \mathrm{~N}$ ).

\begin{tabular}{|c|c|c|c|c|}
\hline Objects & Case A & Case B & Case C & Case D \\
\hline Bending strain $w(\mathrm{~mm})$ & 0.92 & 0.75 & 0.80 & 0.85 \\
\hline Maximum von Mises equivalent stress ( $\mathrm{MPa})$ & 309 & 323 & 306 & 299 \\
\hline Bending force $P(\mathrm{~N})$ & 700 & 700 & 700 & 700 \\
\hline
\end{tabular}
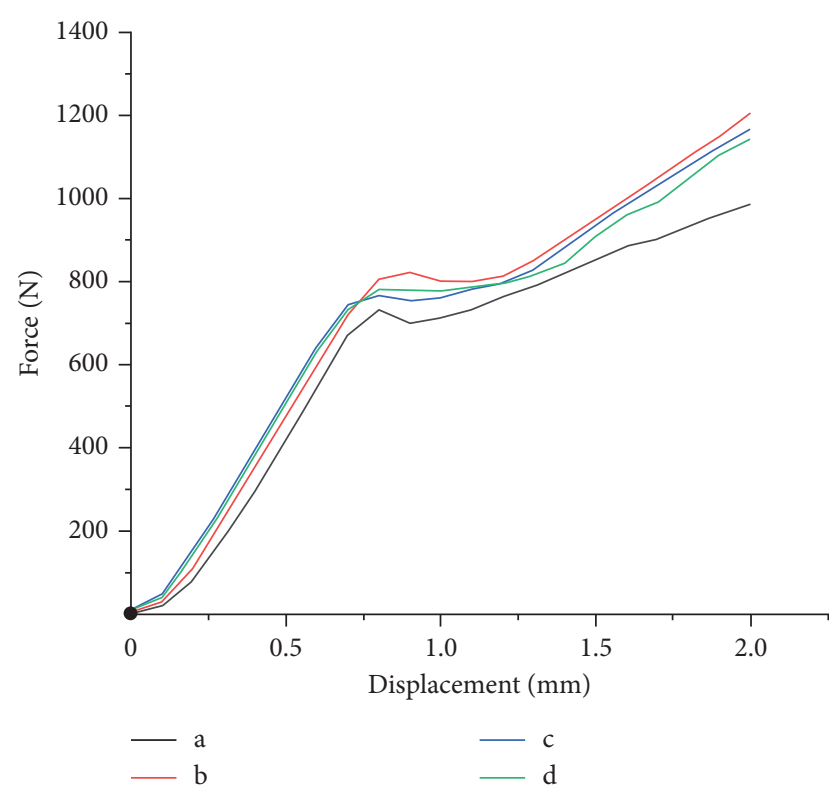

Figure 12: Results of bend test. (a) Case A. (b) Case B. (c) Case C. (d) Case D.

TABle 13: Results of mechanical bend tests.

\begin{tabular}{|c|c|c|c|c|}
\hline Objects & Case A & Case B & Case $\mathrm{C}$ & Case D \\
\hline Load not exceeding the elastic properties of the metal $(\mathrm{N})$ & 699 & 821 & 787 & 767 \\
\hline Maximum applied load at deflection of $2 \mathrm{~mm}(\mathrm{~N})$ & 986 & 1206 & 1167 & 1142 \\
\hline
\end{tabular}


TABLE 14: Comparison of results of mechanical bend tests and computational modeling.

\begin{tabular}{lllll}
\hline Objects & Case A & Case B & Case C & Case D \\
\hline Deflection of samples is $0.5 \mathrm{~mm}$ & & & \\
Calculated bending force (N) & 431 & 572 & 550 & 519 \\
Measured bending force (N) & 417 & 560 & 531 & 511 \\
& 3.24 & 2.09 & 3.45 & 1.54 \\
Difference (\%) & & & \\
Deflection of samples is 1 mm & & & 798 & 776 \\
Calculated bending force (N) & 732 & 808 & 777 & 761 \\
Measured bending force (N) & 713 & 801 & 777 \\
Difference (\%) & 2.59 & 0.86 & 2.63 & 1.93 \\
Deflection of samples is 1.5 mm & & & \\
Calculated bending force (N) & 875 & 979 & 963 & 954 \\
Measured bending force (N) & 852 & 950 & 936 & 909 \\
Difference (\%) & 2.62 & 2.96 & 2.81 & 4.71 \\
Deflection of samples is 2 mm & & & & \\
Calculated bending force (N) & 1033 & 1280 & 1217 & 1167 \\
Measured bending force (N) & 986 & 1206 & 1167 & 1142 \\
Difference (\%) & 4.54 & 5.78 & 4.11 & 2.14 \\
\hline
\end{tabular}

\section{Conclusions}

The results of experiments and computer simulations of elastoplastic deformation established that local laser processing with melting of surface can be used for strengthening of structural elements made from thin sheet steel C22E by up to $8.4 \%$ and for decreasing its deflection under similar workloads by up to $17 \%$, as an alternative to the application of complex geometric shapes, additional strengthening elements, or heat treatment. In this case, the strength of metal sheet parts was improved due to local changes in the microstructure and properties of the material. The hardness of the steel in the processed areas increased by up to $50 \%$ compared to untreated areas, which led to an increase of strength in the laser-processed metal sheet and the maximum level of bending load, which could be endured without plastic deformation.

This study establishes that the mechanical strength of thin sheet steel depends on and can be altered by the parameters of laser processing, the area, and the number of laser tracks. The difference in spacing between laser tracks affects the degree of increase of mechanical strength of thin sheet steel. Thus, the FEA method and the proposed model can be used for the calculation of preliminary information and prediction of the required laser treatment area (geometry and localization of processed area, depth of laser penetration, orientation, and quantity of laser tracks) on the particular material, using a numerical simulation instead of a complex and lengthy experimental selection of treated layer depth and treatment area for strengthening of thin sheet steel. The modeling and bending test results correlate with each other. The maximum difference between the experimental and computational modeling results is less than $6 \%$.

\section{Data Availability}

No data were used to support this study.

\section{Conflicts of Interest}

The authors declare no conflicts of interest.

\section{References}

[1] Worldsteel Association, 2019, https://www.worldsteel.org/ media-centre/press-releases/2019/Global-crude-steel-outputincreases-by-4.6--in-2018.html.

[2] Worldstainless, 2019, http://www.worldstainless.org/news/ Show/2351.

[3] V. N. Feschenko, Constructor Reference. Book 1. Machines and Mechanisms, Infra-Inzheneriya: Moscow-Vologda, Moscow, Russia, 978-5-9729-0084-8, 2016.

[4] G. A. Vorobeva, E. E. Skladnova, V. K. Erofeev, and A. A. Ustinova, Structural Steel and Alloys, St. Petersburg Polytechnic University, Saint Petersburg, Russia, 978-5-73251010-2, 2013.

[5] I. Tylek and K. Kuchta, "Mechanical properties of structural stainless steels. Technical transaction," Civil Engineering, vol. 111, pp. 59-80, 2014.

[6] A. Rzhanicyn, Calculation of Structures Based on the Plastic Properties of Materials, State Publishing House of Literature on Construction and Architecture, Moscow, Russia, 2nd edition, 1954.

[7] A. Valiullin, Limit Elastoplastic Bending of the Beam. Mechanical Engineering And Instrumentation, Metrology, pp. 70-75, Bulletin of Kazan Technological University, 2012.

[8] R. Jones, Mechanics of Composite Materials, Taylor \& Francis, Abingdon, UK, 2nd edition, 1999.

[9] S. A. Kurkin and G. A. Nikolaev, Welded Constructions. Manufacturing Technology, Mechanization, Automation and Quality Control in Welding Production, AAS High School Student Council, Moscow, Russia, 5-06-001906-3, 1991.

[10] L. Guo, S. Yang, and H. Jiao, "Behavior of thin-walled circular hollow section tubes subjected to bending," Thin-Walled Structures, vol. 73, pp. 281-289, 2013.

[11] D. Höche, J. Kaspar, and P. Schaaf, "Laser nitriding and carburization of materials," in Woodhead Publishing Series in Electronic and Optical Materials. Laser Surface Engineering. Processes and Applications, D. G. Waugh and J. Lawrence, Eds., Woodhead Publishing, Cambridge, UK, pp. 33-58, 2015.

[12] P. L. Zhang, H. Yan, P. Q. Hu, Z. S. Yu, C. G. Li, and Q. M. Lu, "Effect of laser surface hardening on the mictrostructure, hardness, wear resistance and softening of a low carbon steel," Lasers in Engineering, vol. 28, pp. 135-149, 2014.

[13] P. D. Babu, G. Buvanashekaran, and K. R. Balasubramanian, "Experimental studies on the microstructure and hardness of laser transformation hardening of low alloy steel," Transactions of the Canadian Society for Mechanical Engineering, vol. 36, no. 3, pp. 241-258, 2012.

[14] D. Zhang and L. Guan, "Laser ablation," in Comprehensive Materials Processing, S. Hashmi, G. F. Batalha, C. J. Van Tyne et al., Eds., vol. 4, pp. 125-169, Elsevier, Amsterdam, Netherlands, 2014.

[15] J. C. Ion, "Laser transformation hardening," Surface Engineering, vol. 18, no. 1, pp. 14-31, 2002.

[16] A. K. Nath and S. Sarkar, "Chapter 11-laser transformation hardening of steel," in Advances in Laser Materials Processing, J. Lawrence, Ed., pp. 257-298, Woodhead Publishing, Cambridge, UK, 2nd edition, 2018.

[17] M. Penchal Reddy, R. A. Shakoor, G. Parande et al., "Enhanced performance of nano-sized $\mathrm{SiC}$ reinforced $\mathrm{Al}$ metal matrix nanocomposites synthesized through microwave 
sintering and hot extrusion techniques," Progress in Natural Science: Materials International, vol. 27, no. 5, pp. 606-614, 2017.

[18] V. Ya Panchenko, Laser Technologies for Processing Materials: Modern Problems of Fundamental Research and Applied Developments, Fizmatlit, Moscow, Russia, 978-5-9221-1023-5, 2009.

[19] V. S. Kovalenko, L. F. Golovko, G. V. Merkulov, and A. I. Strizhak, Laser Beam Hardening, Tehnika, Kyiv, Ukraine, 1981.

[20] O. Kapustynskyi, N. Višniakov, O. Černašèjus, L. Golovko, and V. Chayeuski, "Optimization of the parameters of local laser treatment for the creation of reinforcing ribs in thin metal sheets," in Proceedings of 24th International Conference "MECHANIKA 2019", pp. 71-75, Kaunas, Lithuania, May 2019.

[21] F. Huang, L. D. Yang, Y. H. Rong, and Z. H. Guo, "Effect of carbon content and microstructural refinement on the mechanical property of quenching-partitioning-temperingtreated steels," Materials Research Innovations, vol. 19, no. 4, pp. 54-58, 2015.

[22] V. L. de la Concepción, H. N. Lorussoab, and H. G. Svoboda, "Effect of carbon content on microstructure and mechanical properties of dual phase steels," Procedia Materials Science, vol. 8, pp. 1047-1056, 2015.

[23] European Committee for Standardisation, EN 10083-2:2006, Steels for Quenching and Tempering-Part 2: Technical Delivery Conditions for Non Alloy Steels, German Institute for Standardization, Berlin, Germany, 2006.

[24] N. Višniakov, G. Mikalauskas, O. Černašejus, and J. Škamat, "Laser welding of copper-niobium microcomposite wires for pulsed power applications," Materialwissenschaft und Werkstofftechnik, vol. 50, no. 5, pp. 646-662, 2019.

[25] E. George, Totten. Steel Heat Treatment: Equipment and Process Design, CRC Press, Boca Raton, FL, USA, 978-0-84938453-0, 2006.

[26] M. A. Montealegre, G. Castro, P. Rey, J. L. Arias, P. Vazquez, and M. González, "Surface treatments by laser technology," Contemporary Materials, vol. 1, no. 1, pp. 19-30, 2010.

[27] J. H. Abboud, Y. B. Khaled, H. Julifkar, and M. S. J. Hashmi, "Material response with high power laser in surface treatment of ferrous alloys," in Reference Module in Materials Science and Materials Engineering, Elsevier, Amsterdam, Netherlands, 2017.

[28] International Organization for Standardization, ISO 6892-1: 2016: Metallic Materials-Tensile testing-Part 1: Method of Test at Room Temperature, International Organization for Standardization, Geneva, Switzerland, 2016.

[29] International Organization for Standardization, ISO 4516: 2002: Metallic and Other Inorganic Coatings-Vickers and Knoop Microhardness Tests, International Organization for Standardization, Geneva, Switzerland, 2002.

[30] International Organization for Standardization, ISO 7438 : 2016: Metallic materials-Bend Test, International Organization for Standardization, Geneva, Switzerland, 2016.

[31] FEA-CAE-Engineering.com, DeepSoft, LLC. Engineering Analysis \& Design, 2020, http://fea-cae-engineering.com/feacae-engineering/element_types.htm.

[32] R. M. Jones, Deformation Theory of Plasticity, Bull Ridge Publishing, Blacksburg, VA, USA, 978-0-9787223-1-9, 2009.

[33] N. Višniakov, "Modeling of thermal-strainal processes in a multipass butt-welded thick-walled designs," Mechanika, vol. 5, no. 43, pp. 52-56, 2003.
[34] A. A. Zhukov, A. P. Luzhnikov, and S. Y. Dyinkina, Engineering Materials, pp. 8-15, Mashinostroenie, Moscow, Russia, 1967.

[35] L. I. Dvorkin, Building Materials Science, Moscow-Vologda, Moscow, Russia, 978-5-9729-0176-0, 2017.

[36] D. S. Tsiklis, Technique of Physical and Technical Research at High and Ultrahigh Pressures, Himiya, Moscow, Russia, 1965.

[37] J. R. Cahoon, W. H. Broughton, and A. R. Kutzak, "The determination of yield strength from hardness measurements," Metallurgical Transactions, vol. 2, pp. 1979-1983, 1971.

[38] J. R. Cahoon, "An improved equation relating hardness to ultimate strength," Metallurgical and Materials Transactions, vol. 3, no. 11, p. 3040, 1972.

[39] E. J. Pavlina and C. J. Van Tyne, "Correlation of yield strength and tensile strength with hardness for steels," Journal of Materials Engineering and Performance, vol. 17, pp. 888-893, 2008.

[40] Interstate Standard. GOST 8233-56, Steel. Microstructure Standards, IPK Izdatelstvo Standartov, Moscow, Russia, 1956.

[41] M. Aronovich and Yu. Lahtin, Fundamentals of Metallurgy and Heat Treatment, Metallurgizdat, Moscow, Russia, 1952.

[42] International Organization for Standardization, ISO 643:2012: Steel-Micrographic Determination of the Apparent Grain Size, International Organization for Standardization, Geneva, Switzerland, 2012. 